\title{
Sexualidade na Medida Socioeducativa de Internação: traçando Pistas por uma Revisão da Literatura
}

\author{
Aline Monteiro Garcia ${ }^{1}$ \\ ${ }^{1}$ Universidade Estácio de Sá, RJ, Brasil.
}

\author{
Hebe Signorini Gonçalves ${ }^{2}$ \\ ${ }^{2}$ Universidade Federal do Rio de Janeiro, RJ, Brasil.
}

Resumo: A questão da norma se encontra agravada em se tratando do assunto sexualidade na adolescência, e mais ainda, da adolescência privada de liberdade. O objetivo deste trabalho é mapear a produção bibliográfica acerca do modo como os profissionais do sistema socioeducativo lidam com as expressões da sexualidade dos adolescentes em cumprimento de medida de internação. Foram realizadas buscas em diversas bases de dados online, utilizando diferentes combinações entre as palavras-chave sexualidade, adolescentes, socioeducativo, direitos sexuais e direitos reprodutivos, e nos deparamos com a escassez de trabalhos sobre o tema. Os artigos e textos localizados serão aqui discutidos através de uma proposta temática, visto que sua leitura permite evidenciar as forças que compõem o cenário da sexualidade adolescente na privação de liberdade, fazendo emergir como temas de análise: a sexualidade como direito, as práticas dos profissionais no sistema socioeducativo, e a questão da visita íntima. Foi marcante o entendimento dos profissionais de que trabalhar a sexualidade não faz parte da socioeducação, sendo esta tomada como um problema a ser evitado. No que diz respeito aos espaços de privação da liberdade, pode-se dizer que o funcionamento disciplinar que submete os adolescentes, opera esquemas de vigilância e controle da sexualidade, instituindo micropenalidades cotidianas aplicáveis a todo e qualquer desvio. Os profissionais lidam com a questão pela via da disciplina e do controle, em detrimento da autonomia e do prazer, evidenciando o quanto estamos distantes da garantia do protagonismo juvenil nas decisões políticas que lhes dizem respeito.

Palavras-chave: Sexualidade, Adolescentes, Socioeducativo, Direitos Sexuais, Direitos Reprodutivos. 


\title{
Sexuality in the Socio-Educational Measure of Internment: tracing Clues for a Literature Review
}

\begin{abstract}
The question of the norm is aggravated when the matter is the sexuality in adolescence, and even more, sexuality in adolescence while being deprived of freedom. The objective of this work is to map the bibliographical production about how the professionals of the socio-educational system deal with the expressions of adolescents' sexuality in socio-educational internment. We searched several online databases, using different combinations of the keywords sexuality, adolescents, socioeducational, sexual rights and reproductive rights, and we found few works on the matter. The articles and texts were discussed through a thematic proposal, since their reading allowed to highlight the forces that make up the scenario of adolescents' sexuality in the deprivation of freedom, making emerge as themes of analysis: sexuality as a right, practices of professionals in the socio-educational system, and the question of the intimate visit. The professionals' understanding that working on sexuality is not part of socioeducation was remarkable, and this is taken as a problem to be avoided. Regarding deprivation of liberty spaces, it can be said that the disciplinary functioning to which adolescents are submitted, operates schemes of surveillance and control of sexuality, instituting daily micropenalties applicable to any deviation. Professionals deal with the issue through discipline and control, in the detriment of autonomy and pleasure, evidencing how far we are from guaranteeing youth protagonism in the political decisions related to this young population.
\end{abstract}

Keywords: Sexuality, Adolescence, Socio-educational, Sexual Rights, Reproductive Rights.

\section{Sexualidad en la Medida Socioeducativa de Internación: trazando Pistas por una Revisión de la Literatura}

Resumen: La cuestión de la norma se ve agravada por el tema sexualidad en la adolescencia, y más aún, de la adolescencia privada de libertad. El objetivo de este trabajo es mapear la producción bibliográfica acerca del modo como los profesionales del sistema socioeducativo se ocupan de las expresiones de la sexualidad de los adolescentes en cumplimiento de medida de internación. Se realizaron búsquedas en diversas bases de datos online, utilizando diferentes combinaciones entre las palabras clave sexualidad, adolescentes, socioeducativo, derechos sexuales y derechos reproductivos, y nos encontramos con la escasez de trabajos sobre el tema. Los artículos y textos localizados serán discutidos aquí a través de una propuesta temática, ya que su lectura permite evidenciar las fuerzas que componen el escenario de la sexualidad adolescente en la privación de libertad, haciendo emerger como temas de análisis: la sexualidad como derecho, las prácticas de los profesionales en el sistema socioeducativo, y la cuestión de la visita íntima. Es significativo el entendimiento de los profesionales de que trabajar la sexualidad no forma parte del sistema socioeducativo, siendo ésta tomada como un problema a ser evitado. En lo que se refiere a los espacios de privación de libertad, se puede decir que el funcionamiento disciplinario que somete a los adolescentes, opera esquemas de vigilancia y control de la sexualidad, instituyendo micropenalidades cotidianas aplicables a cualquier desviación. Los profesionales se ocupan de la cuestión por la vía de la disciplina y del control, en detrimento de la autonomía y del placer, evidenciando cuán lejos estamos de la garantía del protagonismo juvenil en las decisiones políticas que les conciernen.

Palabras clave: Sexualidad, Adolescentes, Socioeducativo, Derechos Sexuales, Derechos Reproductivos. 


\section{Introdução}

Em A escrita da História, Burke (1992) detém-se na análise dos sentidos da corrente conhecida como nova história, das armadilhas e dos avanços que ela suscitou entre os historiadores. Conquanto haja interpretações muito diversas e ainda que seu sentido não seja estabelecido, a nova história, para o autor, traz para primeiro plano a preocupação com a experiência comum, contrastando o cotidiano dos grupos, os valores que os regem e os modos como organizam o cotidiano. Questões como cor, credo, classe ou sexo, usualmente examinados a partir de pontos de vista particulares, podem conquistar outra dimensão de análise quando a percepção dos conflitos - tão usuais nesses territórios - são trazidos à tona.

A sexualidade, como lembra Burke, carrega conflitos derivados do campo moral que a fizeram silenciar, tal como nos ensinou Foucault (1979) - com mais força quando se trata da sexualidade adolescente, ou de territórios onde o prazer não deve habitar, como as prisões. Que dizer do sexo dos adolescentes que habitam o espaço socioeducativo, esse que se assemelha à lógica prisional? Para trazer a primeiro plano essa questão, será preciso aceitar o desafio de fazer ver as malhas morais que - já discutidas no sexo, na adolescência e na prisão - ganham nova dimensão quando postas em conexão.

Esse rápido introito serve para fazer ver uma primeira questão: a escassez de bibliografia sobre o tema, indício primeiro de seu silenciamento. Pois, ainda que a sexualidade tenha preocupado mentes e mobilizado afetos no seio da sociedade ao longo da história, ela se constitui ao mesmo tempo como polêmica política, religiosa e educacional, deixando-se contaminar por supostas verdades que visam a construção de modos hegemônicos de viver a sexualidade.

Com o advento do Estatuto da Criança e do Adolescente (ECA) em 1990 (Lei No 8.069), crianças e adolescentes passaram a ser reconhecidos como sujeitos de direitos, seres em desenvolvimento e, nessa condição, merecedores da proteção da família, da sociedade e do Estado. Ainda assim, quando se trata de direitos sexuais do adolescente, os aspectos normativos é que são evidenciados; entre os adolescentes privados de liberdade, a ênfase normativa é ainda mais relevante.

Para Foucault (1987), o poder da norma culmina no século XVIII, quando das regularidades emergiram os sistemas de regras que caracterizam a sociedade disciplinar. Justamente porque assentada em regula- ridades, a regra se afirma como natural e opera a gradação de diferenças individuais, num movimento que ao mesmo tempo individualiza, medindo os desvios, e obriga à homogeneidade, tornando úteis as diferenças e ajustando-as umas às outras. No que diz respeito aos espaços de privação da liberdade, pode-se dizer que o funcionamento disciplinar que submete os adolescentes opera esquemas de vigilância e controle da sexualidade, instituindo micropenalidades cotidianas aplicáveis a todo e qualquer desvio.

O Estatuto trouxe um avanço jurídico-normativo, dispondo-se a enfrentar as contradições sociais que antecederam sua promulgação. Essa mudança visava romper com a doutrina da situação irregular, na tentativa de reduzir a diferença entre os segmentos sociais, e as discriminações daí decorrentes, bem como deslocar o lugar do poder público como mero corretor dos desvios de conduta, adotando a concepção de cidadania ampliada, mais alinhada às normativas internacionais (Gonçalves, \& Garcia, 2007).

Ainda que o ECA coloque, em seu art. 15, que "a criança e o adolescente têm direito à liberdade, ao respeito e à dignidade como pessoas humanas em processo de desenvolvimento e como sujeitos de direitos civis, humanos e sociais", as práticas ainda distinguem o adolescente do "menor". O modo de funcionamento disciplinar ainda impera em todo o tecido social e no que diz respeito ao trato da sexualidade - opera segundo uma norma restritiva e moralizante, especialmente entre os adolescentes das classes menos favorecidas. Para exemplificar, lembramos que a gravidez entre adolescentes de baixa renda é frequentemente examinada pelo viés moral, o que acentua a culpabilização individual dessas jovens e reduz a relevância das políticas públicas na sua proteção (Gonçalves, \& Garcia, 2007). Quando se trata de adolescentes privados de liberdade, isso parece ainda mais grave: o modo de funcionamento disciplinar, evidente nas instituições encarregadas de fazer cumprir a medida judicial, silencia a sexualidade.

Pelo texto legal isso não se justifica, visto que em seu art. $7^{\circ}$ o ECA (Lei no 8.069) afirma que "a criança e o adolescente têm direito à proteção à vida e à saúde, mediante a efetivação de políticas sociais públicas que permitam o nascimento e o desenvolvimento sadio e harmonioso, em condições dignas de existência”. Os discursos e as práticas observados nas unidades de internação sugerem que o exercício da sexualidade se 
encontra apartado do "desenvolvimento sadio e harmonioso" referido no texto legal.

A paternidade também é muito presente entre os rapazes, que enunciam claramente o desejo de serem pais como possibilidade de deslocamento do lugar infantil para a posição adulta, assumindo responsabilidades e experienciando autonomia. Muitos colocam o filho como a grande motivação para repensar a vida, traçar novos objetivos e sair da ilicitude. Ainda que esse posicionamento possa nos parecer estranho, pois, à primeira vista, subverte expectativas sociais - primeiro planejar, depois casar e só então ter filhos -, ele deve ser acolhido e tratado com respeito, visto que pode estar expressando a busca ativa da autonomia possível para esses jovens. Dar tratamento moral a esses discursos seria pouco eficaz mesmo em termos de planejamento familiar e prevenção de doenças sexualmente transmissíveis. (Gonçalves, \& Garcia, 2007).

Porém, há que se compreender que a questão não é simples: reconhecer a capacidade de crianças e adolescentes para o exercício de direitos sexuais não abole as diferenças entre eles e os adultos, evidenciando que não se trata de uma capacidade absoluta (Arantes, 2011).

Este artigo traz alguns estudos relacionados às práticas e ao trato da sexualidade entre adolescentes em conflito com a lei que evidenciam os diversos aspectos que compõem essa trama. O objetivo do trabalho é mapear a produção bibliográfica acerca do modo como os profissionais do sistema socioeducativo, em especial, lidam com as expressões da sexualidade dos adolescentes em cumprimento de medida de internação.

\section{Metodologia}

Entre os meses agosto a outubro de 2015, maio a julho de 2016 e fevereiro de 2017 foram realizadas buscas nas bases de dados SciELO, BVS-psi, Google Acadêmico, Biblioteca de Saúde Pública da Fiocruz e nas bases de teses e dissertações da Universidade Federal do Rio de Janeiro (UFRJ), Universidade Federal Fluminense (UFF) e Universidade do Estado do Rio de Janeiro (UERJ), utilizando diferentes combinações entre as palavras-chave "sexualidade", "adolescentes", "socioeducativo", "direitos sexuais" e "direitos reprodutivos", em todos os índices.

A busca integrada no portal SciELO, com as palavras-chave "sexualidade", "adolescentes" e "socioe- ducativo", trouxe somente um resultado (Bastos \& Marin, 2014). A busca no mesmo portal somente com a palavra "sexualidade" obteve 1170 produções, dentre resenhas de livro, entrevistas e artigos que tratam a sexualidade desde o viés psicanalítico, passando pela educação sexual, prevenção da gravidez, DSTs/ AIDS e saúde reprodutiva, bem como discussões que relacionam gênero, raça e sexualidade, porém, fora do sistema socioeducativo. Portanto, tais trabalhos não serão discutidos nesta revisão. A partir desses achados, vale ressaltar o quão relevante o assunto sexualidade se mostra no meio acadêmico, em contraste com o silêncio acerca da sexualidade do adolescente privado de liberdade. Como veremos a seguir, poucos trabalhos tratam especificamente a questão, evidenciando um campo que demanda aprofundamento.

A busca via Google Acadêmico no portal SciELO, além de artigos encontrados em outras bases que serão mencionados a seguir, trouxe um trabalho de conclusão de curso de especialização (França, 2013) que busca identificar, através de entrevistas com profissionais das diferentes categorias, como a equipe multiprofissional de uma unidade de internação socioeducativa trabalha questões referentes aos direitos sexuais junto a adolescentes em privação de liberdade.

Trouxe também uma dissertação de mestrado em Serviço Social (Franco Netto, 2008) na qual a autora examinou as práticas dos profissionais de saúde que atuam em uma unidade de internação, no que diz respeito à saúde sexual e reprodutiva. Esses dois trabalhos serão tratados de modo mais detalhado nesta revisão, por se deterem especificamente na temática delineada.

A busca no portal BVS Psicologia Brasil com as palavras-chave "sexualidade", "adolescentes" e "socioeducativo" só reportou o mesmo único resultado identificado na base SciELO. Utilizando as palavras-chave "sexualidade" e "adolescentes" foram encontrados 214 resultados nas bases de textos completos e 135 resultados nas bases bibliográficas. Os artigos que relacionavam sexualidade e adolescência como grandes áreas, sem adentrar o campo dos direitos; os que explicavam o ato infracional pelo viés psicanalítico; os que tratavam da sexualidade no ambiente escolar; e os que enfocavam a prevenção de DSTs e AIDS foram excluídos. Dessa busca, dois artigos serão objeto de análise: "Direitos sexuais de crianças e adolescentes: avanços e entraves” (Carva- 
lho, Silva, Jobim e Souza, \& Salgado, 2012) e "Exercício da sexualidade por adolescentes em ambientes de privação de liberdade" (Mattar, 2008).

A consulta ao acervo bibliográfico da biblioteca de Saúde Pública da Fiocruz, com as palavras-chave "sexualidade", "adolescentes" e "socioeducativo", não reportou nenhum trabalho. Com as palavras "sexualidade; adolescentes" foram encontrados 10 trabalhos no eixo Integralidade, três no Educação em Saúde e quatro teses; no entanto, nenhum deles se aproximava do âmbito socioeducativo, portanto, também foram excluídos.

A busca realizada na Biblioteca Digital de teses e dissertações da UERJ, com as palavras-chave "sexualidade", "adolescentes" e "socioeducativo" trouxe uma dissertação de mestrado (Leite, 2009) que, apesar de não se deter no âmbito socioeducativo, aponta importantes reflexões sobre a temática tratada nesta revisão, pois aborda a visão de conselheiros de direitos sobre a sexualidade adolescente.

A consulta à base minerva da UFRJ, com as palavras-chave "sexualidade", "adolescentes" e "socioeducativo" não trouxe nenhum resultado; porém, encontramos 52 trabalhos que continham somente a palavra "sexualidade", 106 com a palavra "adolescentes" e três que continham "socioeducativo". Vale ressaltar que nenhum destes três trabalhos abordava a questão da sexualidade, tratando da violência institucional na execução da medida, da construção de identidade entre os internos e de meninos de rua. Dentre os trabalhos localizados somente a partir da palavra "sexualidade", foi encontrada uma dissertação de mestrado (Moraes, 2001) que dialoga com a temática tratada aqui.

Na Biblioteca Digital de teses e dissertações da UFF, com as palavras-chave "sexualidade", "adolescentes" e "socioeducativo", a busca simples trouxe 74 resultados. Alguns tratavam do cumprimento da medida socioeducativa, evidenciando o quanto a execução da política se distancia do modelo legal; outros tratavam das representações e identidades de jovens que vivem nas ruas e dos autores de atos infracionais; outros se referiam à violência sexual contra crianças e adolescentes, bem como à sexualidade nas escolas.

Através das buscas realizadas com as palavras-chave "direitos sexuais", "direitos reprodutivos" e "socioeducativo", no Google e Google acadêmico destacamos dois estudos que tratavam da visita íntima, de modo legal, conceitual e crítico (Lima, Severo, \&
Maciel, 2013; Barbosa, 2015) e um artigo que fazia uma análise etnográfica do modo como o exercício da sexualidade acontece e é tratado pelos profissionais em um centro socioeducativo de João Pessoa-PB (Pereira, 2016). Este último será abordado de modo mais detido, pois traz uma discussão que inclui a visita íntima e a excede, abordando o manejo dos profissionais em relação à sexualidade dos adolescentes no cotidiano da unidade. Ainda no Google foi encontrado um monitoramento em 13 unidades de internação e internação provisória, localizadas em sete estados das cinco regiões do país, visando produzir informações acerca da garantia dos direitos sexuais e direitos reprodutivos dos jovens em cumprimento de medida socioeducativa (Franco, 2012).

\section{Percorrendo as pistas}

Os artigos e textos localizados na busca serão aqui discutidos através de uma proposta temática, visto que sua leitura permite evidenciar as forças que compõem o cenário da sexualidade adolescente na privação de liberdade. Na intenção de destacar o modo de tratamento da questão, serão analisados os seguintes temas: a sexualidade como direito, abordando a história dos direitos da infância e juventude, os direitos sexuais e reprodutivos e a tensão entre a autonomia e a tutela do adolescente; as práticas e as dificuldades dos profissionais no sistema socioeducativo, com ênfase nos impasses relativos ao manejo da sexualidade adolescente nos espaços de privação de liberdade; a problematização interseccional juventude/gênero/sexualidade no sistema socioeducativo e, finalmente, a questão da visita íntima.

\section{A sexualidade adolescente como direito}

A legislação brasileira segue a normativa internacional no que diz respeito ao sistema de defesa e garantias dos direitos de crianças e adolescentes, adotando princípios semelhantes na Constituição de 1988 e no ECA. No entanto, a legislação nacional é pouco explícita quanto ao exercício da sexualidade entre crianças e adolescentes, o que termina por se constituir em mais um entrave para ações afirmativas no campo.

A título de exemplo destacamos que, em se tratando de sexualidade, crianças e adolescentes são considerados sujeitos de direitos apenas de modo indireto, uma vez que sua sexualidade é nomeada 
no ECA entre os dispositivos vinculados à saúde, - a garantia de privacidade, a preservação do sigilo, o consentimento informado e a proteção à vida - e entre os direitos ao respeito e à dignidade - o direito ao respeito, à preservação da imagem, à autonomia, a ideias, crenças e opinião (Franco Netto, 2008). Como se vê, a sexualidade não é expressa como direito, mas subentendida nos ditames legais. Assim, a legislação brasileira é tímida quando comparada a documentos internacionais como a Plataforma de Ação de Pequim (Declaração...., 1995), que autonomiza os direitos sexuais em relação aos direitos reprodutivos, e a revisão do Programa de Cairo (Relatório..., 1994), que aborda os direitos sexuais dos adolescentes de modo direto, específico e detalhado.

Leite (2009) retoma a tradição tutelar no trato da infância no Brasil, que desde a Colônia tomava a criança e o adolescente como objeto de intervenções, para defender que - apesar dos avanços do ECA - a sexualidade ainda é tutelada. Para a autora, o mesmo processo que fez avançar os direitos ainda engatinha quando se trata de sexualidade. Os direitos sexuais deverão, segundo ela, enfrentar um longo percurso de conquistas, não sem se bater com o desafio ético que confronta autonomia e tutela.

Também para Melo (2010), a prática jurídica no campo da infância e adolescência, baseada no princípio da proteção, pouco ou nada trabalha em prol do protagonismo juvenil quando se trata de sexualidade. $\mathrm{O}$ autor afirma que o direito brasileiro trata a questão muito mais pelo viés do direito penal, voltado tão somente à responsabilização dos agressores nos chamados crimes sexuais, sinal do quão forte é o ditame da moralidade. De modo radical, porém necessário, o autor deduz daí que, em nossa sociedade, o enfrentamento da violência sexual contra crianças e adolescentes toma totalmente a cena, deixando pouco espaço para a garantia de seus direitos sexuais e reprodutivos. Arriscamos dizer que, talvez, a sociedade brasileira ainda precise avançar no campo moral para que a legislação torne mais explícitos os direitos sexuais de crianças e adolescentes, reconhecendo-os e garantindo-os de fato. Tal como afirma Leite (2009), trata-se de um longo processo.

Para Melo (2010), o trato da sexualidade exige desconstruir as noções de desenvolvimento, e de sexualidade, que embasam as práticas que a regulam. Desenvolvimento e sexualidade são noções construídas no intuito de produzir efeitos de normalização.
Seguindo nessa linha crítica, o autor toca na ferida do sistema socioeducativo, ressaltando que "a norma não pode ser pensada sem a consideração das práticas disciplinares de instituições que se ocupam de 'cuidar de' e 'proteger' crianças e adolescentes" (p. 48), citando as escolas e os programas socioeducativos como produtores de individualidades normalizadas.

A despeito desses alertas, o fato é que a sexualidade infanto-juvenil é objeto de perseguição disciplinar (Carvalho et al., 2012). Para as autoras, é importante compreender a distinção entre sexo, direitos sexuais e sexualidade, sendo esta última entendida não somente como exercício sexual genital, mas também como espaço de construção da subjetividade: a sexualidade envolve afetividade, autonomia e liberdade. Trata-se, portanto, de um dispositivo construído culturalmente, que revela as expectativas sociais endereçadas aos indivíduos. A indissociação entre e genitalidade e sexualidade "alimenta o 'pânico moral' que ronda crianças e adolescentes em relação à segunda, fazendo com que o comportamento sexual genital seja considerado a única via possível de relação destes sujeitos com sua sexualidade" (Carvalho et al., 2012, p. 73).

No artigo as autoras explicitam, concordando com Melo (2010), que os direitos sexuais são comumente tratados pelo negativo, ou seja, focando na violência sexual e no seu enfrentamento; vista por esse ângulo, a sexualidade termina por configurar um território simbólico mais afeto àquilo que se quer erradicar; perde-se a dimensão de tudo quanto deve ser afirmado nos encontros sexuais: os sentidos, os desdobramentos, as tensões, as negociações entre corpos, as trocas subjetivas. Parece significativo que o trabalho de Carvalho et al. (2012) tenha desvelado esses sentidos ao estudar a experiência de trinta $\mathrm{e}$ duas mães adolescentes, atendidas em duas instituições públicas de saúde no Mato Grosso e no Rio de Janeiro. Escapando dos rótulos "gravidez precoce" e "gravidez indesejada", as falas das adolescentes revelam o desejo das jovens em se tornarem mães, positivando uma vivência usualmente vista como negativa.

Em sua dissertação de mestrado, Leite (2009) evidencia a ideia de processo de construção de crianças e adolescentes como sujeitos de direitos, que emergiu nos discursos dos seus entrevistados. Nas palavras de Adriana Vianna, a autora "traça um panorama inquietante, feito a partir do entrecruzamento entre temas que nos são caros por diversos 
motivos, que vão desde a naturalização das fases ou etapas da vida, até nossas utopias políticas e ferra-

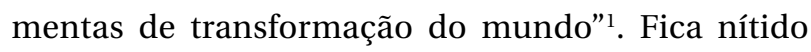
no estudo que a sexualidade, enquanto campo de direitos, ainda se encontra vinculada à reprodução, à violência e às doenças. A ruptura possível - a afirmação da sexualidade como espaço do prazer e da autonomia - parece difícil mesmo entre aqueles que oficialmente têm o papel de efetivar os direitos da infância e adolescência: os conselheiros de direitos.

Seguindo nessa linha, França (2013) constatou que a equipe técnica da unidade de internação pesquisada no estado do Espírito Santo não tinha real dimensão do que sejam direitos sexuais, associando-os somente à visita íntima e ao ato sexual per si. Essa concepção de sexualidade, na visão da autora, impede os profissionais de trabalharem as questões relacionadas à sexualidade que aparecem no cotidiano, não raro desvinculadas do ato sexual.

Nas unidades de internação, onde as regras e a disciplina são vistas como elemento importante no cumprimento da medida, a sexualidade termina revestida da mesma lógica normatizante e cerceadora. É justamente por isso que, para a autora, a sexualidade deveria ser abordada a partir de outro viés: é fundamental que se criem espaços de discussão dos direitos sexuais dentro da unidade, para que o adolescente seja percebido além do seu ato infracional e a equipe possa trabalhar seu empoderamento, a fim de que possa fazer escolhas mais refletidas e autônomas.

Delineado o panorama legal e as discussões e propostas recentes, propomo-nos então a uma análise dos estudos que tratam dos modos de fazer dos profissionais nos ambientes de internação, no que diz respeito à sexualidade dos adolescentes que ali cumprem medida judicial.

\section{O manejo da sexualidade no ambiente socioeducativo de privação de liberdade}

Moraes (2001) desenvolveu um estudo em três instituições de atendimento a jovens, nas quais foram realizadas entrevistas com os profissionais e os jovens beneficiários dos serviços. Esses serviços se caracterizavam como programas de atendimento a uma clientela adolescente em "situação de abandono social", "de rua" ou "carentes", sendo comum a eles o fato de serem recolhidos nas ruas por outros órgãos, ou transferidos de outras instituições. O estudo tinha por objetivo analisar o modo como as instituições representam a vida social e sexual de seu público-alvo; e toma como pano de fundo as novas configurações no atendimento, organizadas a partir da expansão dos movimentos sociais e civis que reivindicam a cidadania da criança e do adolescente. A partir desse ideal humanitário, novas categorias e formas de classificação social são operadas.

Curioso notar o que a pesquisadora afirma sobre a sua entrada no campo. Ela explicitava para os profissionais que a proposta era conversar sobre a sexualidade dos jovens, quando aí percebia de forma nítida o estranhamento dos seus interlocutores. Os profissionais expressavam, inicialmente, que teriam dificuldade para falar sobre e comumente achavam que a psicóloga ou o médico da instituição o fariam melhor.

Outro dado relevante desse estudo foi a constatação de que, mesmo se tratando de serviços abertos, ou seja, os jovens que o frequentam não estão cumprindo medida socioeducativa de privação nem de restrição da liberdade, havia o controle. Isso ficou evidente quando a autora se refere a uma das instituições, que trabalhava com meninas - mães recolhidas nas ruas, que tinham suas atividades externas controladas ou acompanhadas.

A conclusão trazida pelo estudo foi de que os discursos de "cidadania adolescente", do modo como são colocados nos atendimentos, distanciam os profissionais das experiências e biografias desses jovens, o que produz e reproduz essa adolescência como desviante. Mesmo não se tratando de um estudo com profissionais que executam as medidas privativas de liberdade, vê-se aqui muita semelhança com as questões que se colocam nesse campo.

A pesquisa de Leite (2012) explora o modo como os conselheiros de direitos compreendem sexualidade adolescente. Dentre seus achados, a autora verificou que

Todos os interlocutores afirmaram que a grande maioria das instituições não trata formalmente o tema da sexualidade com os adolescentes, de certa maneira negando essa dimensão da vida deles. Quando elas o fazem, é numa perspectiva

${ }^{1}$ Vianna, A. Sexualidade adolescente como ditério? A visão de formuladores de polítiacs públicas: texto de apresentação. 2014. Recuperado de: http://www.clam.org.br/en/books/conteudo.asp?cod=11567 
de prevenção da gravidez e das doenças sexualmente transmissíveis, ou ainda tendo como foco o enfrentamento da violência sexual. [...] Não há uma perspectiva de articular a dimensão sexual a outras na vida dos adolescentes, e essa postura estaria ligada a uma dificuldade dos profissionais em lidarem com o tema. A inabilidade destes, relatada pelos interlocutores, não seria apenas técnica, mas fundamentalmente ética, porque eles estariam imbuídos de preconceitos (Leite, 2012, p. 96).

Além disso, a autora aponta outro importante dado que emergiu da análise: uma "hierarquia de emergências", pela qual os interlocutores afirmam que há muito a ser discutido no campo da infância e adolescência, o que coloca a sexualidade no fim da lista de prioridades.

Sem qualquer pretensão de minimizar a importância do trabalho preventivo, pensamos que é relevante levantar a possibilidade de trabalhar a prevenção como modo de empoderamento e autonomia. Afinal, a decisão de se proteger das doenças sexualmente transmissíveis e utilizar contraceptivos é do adolescente, e essa decisão anuncia uma consideração necessária de sua autonomia, Fica posta a urgência para que os discursos da prevenção incluam a possibilidade de assumir riscos - riscos que os jovens precisam conhecer no âmbito das próprias ações preventivas. No entanto, se balizadas somente pela lógica normalizadora e moralizante, essas ações ficarão limitadas à produção de corpos disciplinados e, em contrapartida, de corpos desviantes, abandonando a perspectiva do autocuidado autônomo.

Pereira (2016) realizou um estudo etnográfico num Centro Socioeducativo em João Pessoa-PB, através do qual percebeu a dificuldade em se implementar ações de âmbito coletivo nessa área dos direitos sexuais e reprodutivos, enfatizando que são feitas pelo esforço e interesse individual dos profissionais, marcada por ações pontuais e pouco articuladas, muitas vezes nem fazendo parte do projeto educativo da instituição.. No Centro estudado, as atividades educativas e preventivas eram trazidas por ONGs ou feitas por iniciativas particulares da equipe de saúde do estabelecimento. Fala também da prática de masturbação que os internos tinham em lugares comuns, como as salas de aula, e os professores respondiam a isso com a necessidade de ensiná-los a controlar seus impul- sos; as professoras usavam um jaleco que, segundo elas, servia para esconder o corpo, protegendo assim sua integridade dos olhares dos adolescentes.

A autora ressalta o quanto a lógica do controle e vigilância dos corpos é enfatizada na abordagem da sexualidade dos internos. Esses elementos também aparecem num estudo que busca identificar como a equipe multiprofissional de uma unidade de internação socioeducativa trabalha as questões referentes aos direitos sexuais com adolescentes em privação de liberdade (França, 2013). A investigação teve lugar em unidades masculina e feminina do município de Cariacica-ES e mostrou que, no ambiente de internação, a sexualidade se apresenta: nas regras rígidas que os adolescentes (meninos) criam para os dias de visita (não levantar a camisa, por exemplo) e para a prática da masturbação (respeitar um dado período após a visita, de modo a assegurar que a masturbação não se valha de fantasias acionadas pela visão de algum familiar); nos envolvimentos amorosos entre internos e internas, já que as unidades masculina e feminina são próximas e os adolescentes criam estratégias de comunicação e flerte com o sexo oposto, seja por sinais à distância, seja nos trajetos em que se encontram; na troca de cartas que, antes permitida e regulada pela equipe técnica, passou a ser feita de forma clandestina a partir do momento em que a equipe a proibiu, sob o argumento de que causava problemas entre as internas.

Uma técnica entrevistada relata que o número de meninas com as quais o interno poderia se corresponder era acordado entre as equipes das unidades, o que revela com clareza o viés moral da interdição; conforme a autora, a troca de cartas era considerada um relacionamento amoroso e, por isso, exigia a restrição a um único correspondente. França (2013) sublinha que os adolescentes eram excluídos dessa decisão, visto que seu desejo não era levado em conta nem trabalhado. Mais uma vez, os adultos decidem por eles, dando ensejo à construção de estratégias clandestinas que permitam que a sexualidade siga se expressando e exercendo.

A preocupação moral com a sexualidade foi observada ainda nos procedimentos que recomendam (e realizam) a leitura da correspondência com as namoradas do mundo externo à unidade de internação, sob o argumento de evitar o contato com conteúdos considerados "nocivos", tais como pedidos de drogas ou acerto de contas com grupos 
rivais. Em contrapartida, a relação sexual desprotegida, admitida pelos próprios adolescentes, ou o sentimento de posse da companheira, que revela forte hierarquia de gênero nas relações amorosas, raramente são abordados.

O que França (2013) coloca em evidência é que a equipe técnica toma decisões e define critérios com pouca discussão, reflexão e embasamento teórico, ao que parece restrita a argumentos morais. Mesmo os episódios de violência sexual são tratados de modo velado e raramente revelados aos técnicos pelo próprio adolescente vitimado. Em seu entender, isso acontece porque a equipe técnica está centrada na produção de pareceres, o que dificulta a formação de vínculos, mas também do crivo moral que emerge quando essas situações vêm à tona, dando curso à culpabilização da vítima, e a inferências de homossexualidade.

Franco Netto (2008) analisou os desafios presentes da prática profissional numa unidade de internação, o Centro de Atendimento Juvenil Especializado do Distrito Federal (CAJE-DF), com foco nos aspectos relativos à saúde sexual e reprodutiva, à luz dos princípios do Sistema Único de Saúde (SUS) e da Doutrina da Proteção Integral. A autora fez visitas à unidade e entrevistou sete profissionais, entre eles médico, enfermeiro, auxiliar de enfermagem, dentista, assistente social e psicólogo. O clima da unidade reflete-se no fato dos adolescentes não usarem uniforme, apesar de haver uma padronização nas cores das roupas, os cabelos dos meninos não são raspados, embora curtos, e as meninas têm cabelos compridos; os adolescentes têm livre circulação e em alguns momentos de lazer meninos e meninas convivem na quadra, onde eles jogam futebol e elas se juntam em grupos de quatro ou cinco, observando os rapazes e escrevendo cartas.

Essas observações mostram que a privação de liberdade pode acolher experiências mais livres e que possibilitem expressões da sexualidade. Assim como no estudo anterior, as cartas geravam brigas entre os adolescentes, e uma técnica explicitou que as meninas mandam várias cartas para vários meninos. Uma das técnicas afirma que as cartas passam pelo crivo da segurança, que verifica se não há algum conteúdo "perigoso" Percebe-se aí que, ainda que haja alguma liberdade, esta é sempre vigiada em uma instituição fechada.
De modo geral o estudo mostra que os profissionais não entendem que trabalhar a sexualidade faça parte da socioeducação. Os discursos circulam entre a negação de que haja relações sexuais e o reducionismo de entender que sexualidade se resume a disponibilizar o preservativo quando o adolescente tem o benefício do "saidão". Nas entrevistas, fica clara a negação de relações homossexuais na unidade, e a equipe afirma que os adolescentes não trazem isso aos atendimentos, embora os técnicos saibam que pode acontecer, ressaltando o quanto isso é estigmatizado entre os meninos. A equipe aborda a sexualidade rapidamente e apenas quando os adolescentes trazem alguma dúvida a respeito, como se quisesse logo 'se livrar' do assunto.

Uma forte evidência do distanciamento do trabalho técnico frente às questões da sexualidade é o fato de o preservativo ser disponibilizado pela administração quando o adolescente tem saídas da unidade, sem que nada seja discutido a respeito. As adolescentes do sexo feminino recebem, além do preservativo masculino, o feminino (que não gostam de usar, segundo os entrevistados) e a pílula anticoncepcional, sendo que algumas falas nas entrevistas mostram uma forte preocupação em evitar a gravidez. As falas dos profissionais trazem certo desconforto quando os adolescentes revelam que não utilizaram o insumo disponibilizado.

A distribuição de preservativos aparece também como um entrave no estudo realizado por Pereira (2016), no qual observou que os profissionais tratam isso com negligência, ainda que os internos expressem o desejo de se protegerem nas relações sexuais, improvisando com o que tem, usando mesmo até sacos de bolacha.

Franco Netto (2008) concluiu que as ações de saúde sexual e reprodutiva são fragmentadas e pontuais, permeadas por controle, advertência, amedrontamento e risco, construídas a partir da visão dos profissionais sobre os adolescentes, vistos como impulsivos, imaturos, promíscuos e incompletos, o que acaba por desqualificar seu universo sociocultural.

Bastos e Marin (2014) investigaram unidades da Fundação de Atendimento Socioeducativo do Pará, partindo das falas que circulam na instituição colocando o trabalho com as adolescentes como muito difícil. Foram entrevistadas cinco adolescentes, o que permitiu verificar que a alegada dificuldade se associava à exposição que as adolescentes faziam dos genitais. $\mathrm{O}$ artigo se vale do referencial psicanalítico, 
afirmando que as adolescentes derivam suas questões da complexa relação com suas mães e que a exposição que elas fazem do corpo é uma maneira de responder às mudanças pubertárias, buscando no outro a oferta de um sentido capaz de levá-las a compreender essas mudanças, ainda que à custa do efeito surpresa que o exibicionismo promove.

O artigo reduz a complexa vivência da sexualidade feminina à relação com a mãe e ao viés desenvolvimentista de estranhamento do corpo pubertário como base da busca de um sentido, via olhar do outro, para esse corpo "estranho". Sem negar que as relações das adolescentes com suas mães de fato poderiam ser complicadas e marcadas por abandono, resumir a isso suas dificuldades retira de cena diversos outros aspectos do universo sociocultural dessas adolescentes. Ou seja, vai ao encontro do que Franco Netto (2008) colheu nas falas dos técnicos entrevistados, em termos de individualização das questões da sexualidade e desqualificação da vivência sociocultural desses jovens.

Partindo desse estado das práticas relativas à sexualidade dos adolescentes internados, passemos agora à análise do modo como se configuram as intersecções entre juventude, gênero e sexualidade no sistema socioeducativo.

\section{Interseccionalidades em questão: moças e rapazes privados de liberdade}

Diante da literatura consultada, é notório o quanto questões de gênero e sexualidade perpassam de modo diverso as unidades masculinas e femininas dos sistemas socioeducativos brasileiros. Tais diferenças aparecem na gestão das relações sexuais entre os/as internos/as, nas discriminações por orientação sexual/identidade de gênero, bem como no tratamento diferenciado que toma por base preconceitos de gênero.

Dado que a noção de gênero aponta para a dimensão relacional do feminino e do masculino, ela transversaliza outras categorias (classe, raça/etnia, geração, entre outros), dando sentido e posicionando-as nas relações hierárquicas e de poder. Por meio das construções de gênero é possível apreender um conjunto de práticas, representações, símbolos, normas e valores sociais elaborados a partir da diferença sexual anatômica e fisiológica percebida (Louro, 1997).

Às questões de gênero somam-se aspectos socioculturais geracionais, que em nossa sociedade colo- cam a adolescência como etapa de transição para o mundo adulto, marcada por crises que devem ser tratadas, na perseguição de um alvo de maturidade fixo e homogêneo. Temos assim o foco no futuro e utilidade à sociedade, que serve à lógica individualista e culpabilizadora da subjetivação capitalística, tão ao gosto do funcionamento neoliberal, no qual ser um adulto de sucesso ou fracasso depende única e exclusivamente do sujeito dar conta da sua etapa crítica (Coimbra, Bocco \& Nascimento, 2005). Em relação aos/às jovens internados/as, vemos que são enviados/as ao sistema as vítimas mais agudas das desigualdades sociais, iniciadas com o processo de escravização brasileiro e agravadas pelo neoliberalismo: negros e moradores de periferias.

Aos olhos dos profissionais que atuam no sistema socioeducativo, esses desviantes são contestadores, rebeldes, cheios de hormônios, impulsivos, raivosos, resistentes; às moças, são direcionados adjetivos como desequilibrada, inconsequente e com nervos à flor da pele, na tentativa de essencializar certa instabilidade do feminino, que aparece de modo mais intenso quando atravessada pelo contexto geracional adolescente (D’Angelo, \& Garay Hernandez, 2017).

$\mathrm{Na}$ interseção entre gênero e geração vemos práticas no sistema socioeducativo que perpetuam as diferenças entre os gêneros instituídas socialmente. Fachinetto (2015) ressalta a questão ao evidenciar que, no projeto lavanderia da Fundação de Atendimento Socioeducativo do Rio Grande do Sul (FASE), as adolescentes lavam as roupas de funcionários e de outros clientes da unidade, além das roupas dos internos da unidade masculina. Outras evidências estão no fato de meninos poderem fumar na instituição, e meninas não; elas não podem jogar futebol, somente vôlei, por ser o futebol considerado esporte muito violento.

Montenegro (2015) também verificou em sua pesquisa a atribuição de tarefas diferentes consoantes o gênero, embasadas no papel naturalizado da mulher como a única executora das tarefas do lar. Falas como "Não se fazem mais meninas como antes" ou "são meninas, que não sabem lavar calcinhas, limpar uma casa, então, são meninas assim que brigam por causa de um doce" (p. 96), aparecem como queixas dos funcionários, inferiorizando as adolescentes por não executarem tais tarefas e elencando isso como um fator que dificulta o trabalho com as internas. A autora ressalta que tais julgamentos não recaem sobre o garoto em cumprimento de medida. 
É por razões como essa que Montenegro (2015) afirma que as desigualdades de tratamento dentro do sistema socioeducativo se baseiam em preconceitos de gênero. Para as mulheres, há dupla reprovação: além do ato infracional, sobre ela recai a decepção por ter descumprido os papéis de mãe, irmã, esposa e filha. A estigmatização da mulher no Brasil, segundo Braustein (2007), sustenta-se em três eixos: ela é inferior, submissa e pecadora.

Em estudo desenvolvido numa unidade de internação feminina da Fundação CASA (SP), Bassi (2011) constatou que as jovens não tinham espaço para expressar sua sexualidade. As manifestações homoafetivas eram vistas como indecência e imoralidade, sendo rechaçadas na mesma medida em que se expressavam. Não havia qualquer trabalho voltado para a sexualidade na institucionalização; a proibição de qualquer troca de carícias ou aproximação excessiva entre as adolescentes e entre elas e os funcionários, expressa no Regimento Interno, resumia as regras no trato da sexualidade. Ainda que pareça óbvio que agentes públicos devem resguardar a integridade das jovens internadas, não é o que vemos na prática: Gonçalves e Mesquita Filho (2015) relatam os assédios sexuais praticados pelos agentes socioeducativos, bem como a existência de relações afetivo-sexuais entre agentes e internas na Fundação CASA. No Rio de Janeiro, D’Angelo e Garay Hernandez (2017) verificaram que algumas internas mostravam os seios para os agentes, em troca de cigarros. Tais práticas articulam a lógica de respeito e submissão à hierarquia masculina, que devem ser interiorizadas pelas jovens (Gonçalves, \& Mesquita Filho, 2015), à lógica de submissão nas unidades de internação.

Bassi (2011) ressalta enorme diferença entre meninos e meninas nos espaços de privação da liberdade: enquanto elas ostentam seus relacionamentos, os garotos escondem ou omitem as relações homoafetivas. A sexualidade é atravessada por uma série de instituições além da socioeducativa, como a mídia, a família, as religiões, e o tráfico de drogas (D`Angel,o \& Garay Hernandez, 2017), que imbricadas com gênero e geração tecem redes diferenciais na privação de liberdade masculina e feminina. Nas unidades masculinas há um cenário onde as regras das facções comandam as condutas sexuais dos internos, tais como a proibição de se masturbar e levantar a camisa em dia de visita, bem como a intolerância com os jovens que cometeram ato análogo ao crime de estupro (Moreira,
2012). O estupro e o desrespeito à visita alheia são vistos com imperdoáveis e passíveis de severa penalização através de agressões físicas.

Tais regras atualizam normas de gênero construídas fora dos muros dos estabelecimentos socioeducativos, nas quais vigora o modelo de masculinidade hegemônica calcado em padrões heteronormativos, utilizado pelas facções, no qual o homem deve portar características como manutenção da honra da família, virilidade e agressividade. Assim, quando rapazes gays são internados, parece haver uma desestabilização na operacionalização das relações (D`Angelo, \& Garay Hernandez, 2017). Nascimento (2010) verificou que a rejeição aos homossexuais acontecia de duas maneiras complementares: hostilização velada, com piadas, gírias pejorativas e isolamento; e situações extremas, como violência física e óbitos. Era comum também que o interno mais fraco fisicamente fosse forçado a ter relações sexuais sem o seu consentimento, sendo assemelhado ao lugar do feminino e, portanto, de submissão.

Silveira Filho (2010) ressalta que os discursos que evidenciam o que se espera de meninos e meninas em função do seu sexo morfológico são impensados e poderosos, e seus usos indiscriminados e pouco refletidos contribuem para a manutenção do binarismo de gênero. Aos homens geralmente são atribuídas características de força, coragem, determinação, enquanto às meninas são dadas a meiguice, ternura e afeição, tornando estranho aquele que não se enquadra nesses repertórios.

O trato da sexualidade na medida de internação é muito influenciado pela perspectiva social de gênero, haja vista que, em algumas instituições do país, só os meninos têm autorização para receber visita íntima (Bassi, 2011). Vemos que a instituição encarregada e socioeducar na verdade perpetua preconceitos e discriminações com base no binarismo de gênero.

\section{A questão da visita íntima: uma "benesse" ou direito?}

Um estudo conduzido por Mattar (2008) focalizou jovens do sexo masculino, privados de liberdade, com destaque para os relatos das experiências sexuais destes, como a masturbação e a visita íntima. Os dados foram produzidos em três estados do nordeste brasileiro (não mencionados pelo autor) que já haviam iniciado a visita íntima, e o artigo visa uma avaliação dessas experiências. Os dados qualitativos colhidos 
evidenciam que o manejo da visita íntima, atrelado ao ambiente físico oferecido pelas unidades para tal, demonstra o quanto "o exercício da sexualidade por meio da visita íntima é absolutamente vigiado, buscando a disciplina dos jovens por meio do controle de seus corpos" (p. 79). O bom comportamento aparece como importante critério balizador nas decisões da equipe técnica em conceder ou não ao adolescente o direito à visita íntima, sendo esta muitas vezes barganhada em termos de prêmio ou castigo.

Pereira (2016) coloca que 16 dos 193 internos da unidade de internação masculina de João Pessoa-PB tinham acesso à visita íntima, mas caso o adolescente se envolvesse em brigas e/ou desobedecesse às regras da instituição, perdia o acesso a esse direito. A autora traz a sua inquietação, já que a visita íntima aqui é colocada em termos de privilégio para os que têm bom comportamento. A visita íntima emerge, então, como um dispositivo de controle dos corpos e da sexualidade, e não enquanto promoção da continuidade do convívio familiar e o fortalecimento dos laços afetivos, não considerando que os adolescentes têm vida sexual ativa antes da internação e que exercerão a sexualidade de qualquer modo, mesmo que sendo proibido pelo estabelecimento.

Mattar (2008) aponta a necessidade de problematizar os discursos e práticas que tendem ao viés punitivo, colocando a visita íntima como uma benesse, um afrouxamento no cumprimento da medida socioeducativa, procedimento que reforça o viés punitivo da socioeducação esquecendo a normativa legal, que aponta o vínculo entre a visita íntima e a socioeducação. $\mathrm{O}$ artigo defende a ideia de que a privação de liberdade, em si, já constitui castigo o suficiente ${ }^{2}$ para fazer o jovem repensar suas atitudes, e que o direito ao exercício da sexualidade não deveria estar necessariamente atrelado ao vínculo constitutivo familiar, merecendo ser exercitado porque é um direito humano como todos os demais.

A defesa desse posicionamento vai de encontro ao modo como atores do Sistema de Garantia de Direitos (SGD) lidam com as questões relativas à sexualidade na infância e adolescência. No site da Secretaria de Direitos Humanos da Presidência da República encontramos a notícia, de agosto de 2014, sobre da realização de uma oficina nacional para consenso sobre saúde sexual e saúde reprodutiva de adolescentes privados de liberdade, em parceria com o Ministério da Saúde. A oficina visava discutir a concepção de saúde integral defendida presente no artigo 60 do Sistema Nacional de Atendimento Socioeducativo - Sinase (Lei № 12.594/2012). Participaram profissionais da área jurídica, da saúde, da educação, representantes do Conselho Nacional dos Direitos da Criança (Conanda), do Fórum Nacional de Dirigentes Governamentais de Entidades Executoras da Política de Promoção e Defesa dos Direitos da Criança e do Adolescente (Fonacriad), do Ministério Público, da Promotoria e da Defensoria Pública das cinco regiões do país.

A Fundação da Criança e do Adolescente - Fundac (Bahia) apresentou o Projeto "Medida Afetiva"', criado para a promoção e garantia dos direitos sexuais e reprodutivos dos adolescentes nas unidades de internação. O objetivo é a garantia do direito à visita íntima ao adolescente interno casado ou em relação estável, como previsto na Lei do Sinase (Lei No 12,594, 2012). Ou seja, a ideia de desvincular a visita íntima do vínculo familiar ainda não circula nas discussões que tratam da implementação de tal direito.

França (2013), em seu estudo numa unidade de internação masculina do Espírito Santo, menciona a visita assistida, momento em que o socioeducando e sua companheira ficam em uma sala, monitorados por um dos técnicos de referência ou por um agente socioeducativo. A visita assistida tem duração de duas horas e, dependendo do socioeducando, pode variar de uma a duas vezes no mês. Não foi pensada a possibilidade de visita íntima por conta da falta de estrutura física e da faixa etária atendida (12 a 16 anos), ainda que a equipe técnica saiba, através dos atendimentos, que a maioria dos adolescentes já tem vida sexual ativa e sem proteção. Na outra unidade, que atende adolescentes de 17 a 21 anos, a visita íntima foi instituída para aqueles com união estável comprovada.

Franco Netto (2008) verificou que numa unidade masculina do Distrito Federal a visita íntima ainda não era institucionalizada, mas a autora coloca que fica claro o consentimento velado por parte da instituição. Os adolescentes que têm namoradas recebem visitas nos dias de semana, que acontecem num salão multiuso, no qual os casais sentam-se de frente um para o

\footnotetext{
${ }^{2}$ Inclusive, o ECA traz em seu art. 94, inciso II, que as entidades que desenvolvem programas de internação têm como obrigação "não restringir nenhum direito que não tenha sido objeto de restrição na decisão de internação".
} 
outro, o que permite o contato físico de mãos, pernas, coxas e abraços, porém com beijos tímidos, já que são vigiados por um agente social e de segurança. Para os que são casados ou têm união estável, as visitas são aos finais de semana, junto com os outros familiares. Aqui, um dos entrevistados afirma que a casa não se organiza para a visita íntima, mas que os quartos ficam abertos, afirmando que não é possível garantir que não haja relação sexual: e que mesmo sem espaço físico adequado, sabe-se que os adolescentes sempre dão um "jeitinho", deixando bem claro que os profissionais fazem "vista grossa" quanto a isso. Curioso notar que tais situações não acontecem com as adolescentes do sexo feminino, através da justificativa de que a maioria delas não tem relação estável, ainda que algumas tenham filhos. Vale ressaltar que nenhum estudo constatou a existência da garantia do direito à visita íntima para as moças internadas.

Uma das dificuldades sempre colocadas como entrave à visita íntima é a falta de estrutura física adequada nas unidades. Porém, o estado de Alagoas nos mostrou que é possível ultrapassar essa barreira, quando o empenho da gestão e o incentivo à participação dos adolescentes foi um diferencial, visto que os internos se mobilizavam na preparação dos alojamentos (limpeza e decoração) para receber a parceira. Mesmo havendo na unidade um espaço destinado à visita íntima, os internos participaram da decisão de mudá-la para o alojamento, onde se sentiam mais à vontade, se revezando no ambiente que já conviviam, sentindo que assim a visita poderia acontecer com mais discrição. Essa experiência evidencia que o jovem é capaz de criar novos sentidos ao espaço, bem como cuidar de si e do outro, quando seu protagonismo é convocado (Franco, 2012).

Através dos estudos mencionados, é perceptível o quanto é difícil e permeada por moralismos a efetivação do direito à visita íntima, ainda que ele esteja expressamente colocado na lei. Critérios são decididos através de argumentos que escapam ao modo como esses adolescentes vivem suas experiências, desejos, crenças e valores, para serem pautados a partir dos valores e vivências dos profissionais. Desse modo, o protagonismo e a autonomia dos adolescentes passam longe quando se trata de sexualidade.

\section{Considerações finais}

Durante a busca de estudos relativos ao modo como os profissionais lidam com a sexualidade dos adolescentes internados, ficou clara a escassez de trabalhos relacionados especificamente ao tema. Somente três estudos focavam a questão nesse ponto. No entanto, outros estudos foram aqui elencados por margearem o assunto e tocarem no modo como os profissionais, sejam eles do sistema socioeducativo ou não, abordam essa temática.

Quanto aos profissionais que atuam no ambiente socioeducativo de internação, a partir dos estudos ficou claro haver o entendimento de que trabalhar a sexualidade não faz parte da socioeducação, sendo esta tomada como um problema a ser evitado. Isso ficou evidente a partir dos modos como os profissionais se colocavam perante tais questões, com dificuldade em se aproximar dos adolescentes para discutir com eles como vivenciavam a sexualidade: na maioria dos casos, os profissionais expressaram distanciamento ao afirmarem que só conversavam sobre isso com eles para responder, tirar dúvidas, ou repreendê-los por não terem utilizado algum insumo fornecido, bem como para alertar sobre os possíveis riscos da vida sexual. O viés disciplinador e moral apareceu como forte balizador das decisões técnicas, em especial na questão das cartas e no modo de trabalhar a entrega de insumos.

Os estudos evidenciam o quanto estamos distantes da garantia do protagonismo juvenil nas decisões políticas que lhes dizem respeito. Os percursos históricos trazidos pelos trabalhos pesquisados apontam os avanços em termos legais, com a passagem, na letra da lei, da doutrina da situação irregular para a da proteção integral, bem como as diversas normativas internacionais que afirmam o protagonismo juvenil. No entanto, também evidenciam o quanto ainda temos a percorrer para nos afastarmos dos moralismos e juízos de valor que orientam as decisões políticas cotidianas. Os operadores do sistema de garantia de direitos acabam por atuar ainda pela lógica da tutela, a partir da qual decidimos pelos jovens o que é melhor para eles, negligenciando assim seus universos de valores, sentidos, significados e vivências, em especial quando se trata da afirmação dos direitos sexuais. Indo mais a fundo, quando interseccionamos sexualidade/gênero e geração, vemos que os sistemas socioeducativos perpetuam práticas embasadas em preconceitos de gênero, perpetuando binarismos, reafirmando a masculinidade hegemônica e o lugar de submissão feminino, em vez de desconstruí-los. 
Tudo isso aparece no âmbito jurídico-normativo quando se trata especificamente dos direitos sexuais na adolescência. Como diversos estudos apontaram, nesse campo a discussão ainda é pouco clara, incipiente, e onde as leis civis colocam severos limites às decisões dos jovens. Parece que as leis se encontram muito distantes do que acontece no cotidiano dos jovens, em especial os das classes populares, que constituem família e vivem a paternidade e a /maternidade de modo muito diferente dos jovens da classe média. A gravidez indesejada, por exemplo, aparece como uma construção social e não como uma realidade per si, como mostraram alguns estudos tratados nessa revisão.

Os discursos e práticas encontrados nos estudos trazem a necessidade de promover a discussão e a reflexão da atuação profissional socioeducativa, quando se trata do exercício da sexualidade dos adolescentes internados. A experiência de Alagoas nos mostra o quanto pode ser positiva a aposta na auto- nomia do adolescente, quando este participa das decisões e consegue vislumbrar novos modos de ocupar os espaços e se colocar na relação com o outro de modo cuidadoso. Podemos ressaltar que a experiência trouxe benefícios para o convívio na unidade, a partir do momento que a visita íntima foi encarada como modo de exercício da autonomia.

Poucos estudos abordam o modo com os socioeducadores lidam com a sexualidade dos adolescentes internados. No entanto, evidenciam as dificuldades dos profissionais em lidar com o tema pelo viés da autonomia e do prazer, de admitir que o que acontece na vida desses jovens é diferente do idealizado. Portanto, fica aqui apontada a importância de desenvolver trabalhos e pesquisas que se direcionem especificamente aos socioeducadores (equipe técnica, agentes, direções), no sentido de promover o mapeamento e a reinvenção/problematização dos critérios que embasam as práticas instituídas em relação à sexualidade dos adolescentes que ali se encontram.

\section{Referências}

Arantes, E. (2011). Pensando a psicologia aplicada à justiça. In: H. Gonçalves, \& E. Brandão (Orgs.), Psicologia jurídica no Brasil (pp. 11-42, 3a ed.). Rio de Janeiro, RJ: NAU.

Barbosa, D. (2015). Direito fundamental à visita íntima do adolescente internado. Revista Liberdades, (19), 69-85.

Bassi, S. (2011). Sexualidade feminina em privação de liberdade: Construindo relações sociais mais autênticas (Dissertação de mestrado). Pontifícia Universidade Católica de São Paulo, São Paulo, SP, Brasil.

Bastos, J., \& Marin, I. (2014). Adolescentes exibicionistas: A busca de um olhar. Revista Latinoamericana de Psicopatologia Fundamental, 17(2), 175-190. https:// doi.org/10.1590/1984-0381v17n2a03

Braustein, H. R. (2007). Mulher encarcerada: Trajetória entre a indignação e o sofrimento por atos de humilhação e violência (Dissertação de Mestrado). Faculdade de Educação, Universidade de São Paulo. São Paulo, SP, Brasil.

Burke, P. (1992). A escrita da História: Novas perspectivas. São Paulo, SP: Universidade Estadual Paulista.

Carvalho, C., Silva, E., Souza, S. J., \& Salgado, R. (2012). Direitos sexuais de crianças e adolescentes: Avanços e entraves. Psicologia Clínica, 24(1), 69-88. https://doi.org/10.1590/S0103-56652012000100006

Coimbra, C., Bocco, F., \& Nascimento, M. (2005). Subvertendo o conceito de adolescência. Arquivos Brasileiros de Psicologia, 57(1), 2-11.

D’Angelo, L., \& Garay Hernandez, J. (2017). Sexualidade, um direito secundário? Atravessamentos entre sexualidade, socioeducação e punição. PLURAL: Revista de Ciências Sociais, 24(1), 78-104. https://doi.org/10.11606/ issn.2176-8099.pcso.2017.125958

Declaração e plataforma de ação da IV Conferência Mundial sobre a Mulher. (1995). Pequim. Recuperado de http://www.onumulheres.org.br/wp-content/uploads/2014/02/declaracao_pequim.pdf

Fachinetto, R. (2015). Relações de gênero no sistema socioeducativo: Uma reflexão a partir da "casa de bonecas". In: A. P. M. Costa, D. D. Eilberg, J. M. Goldani (Orgs.), Justiça juvenil na contemporaneidade (pp. 88-93). Porto Alegre, RS: Universidade Federal do Rio Grande do Sul.

Foucault, M. (1979). Sobre a história da sexualidade. In: M. Foucault, Microfísica do poder (pp. 243-276, 15a ed.). Rio de Janeiro, RJ: Graal.

Foucault, M. (1987). Vigiar e punir (22a ed.). Petrópolis, RJ: Vozes. 
França, W. (2013). Adolescentes privados de liberdade e direitos sexuais: Uma reflexão necessária (Trabalho de conclusão de curso). Universidade Católica de Brasília, Brasília, DF, Brasil.

Franco, M. H. (Coord.). (2012). Direitos sexuais e direitos reprodutivos de adolescentes e jovens em conflito com a lei: Contribuições para o debate e ações. São Paulo, SP: ECOS.

Franco Netto, T. (2008). Direitos sexuais e direitos reprodutivos de adolescentes privados de liberdade: A experiência do CAJE-DF (Dissertação de mestrado). Universidade de Brasília, Brasília, DF, Brasil.

Gonçalves, R., \& Mesquita Filho, J. (2015). Gênero e medida socioeducativa: As jovens dentro e fora de casa. In: Anais da XII Semana da Mulher, Marília, SP: Unesp. Recuperado de https://www.marilia.unesp.br/Home/Eventos/2015/xiisemanadamulher11189/genero-e-medida_rosangela-teixeira-goncalves.pdf

Gonçalves, H., \& Garcia, J. (2007). Juventude e sistema de direitos no Brasil. Psicologia Ciência e Profissão, 27(3), 538-553. https:// doi.org/10.1590/S1414-98932007000300013

Lei No 12.594, de 18 de janeiro de 2012. Institui o sistema nacional de atendimento socioeducativo (SINASE). Diário Oficial da União, 19 jan. 2012. Recuperado de http://www.planalto.gov.br/ccivil_03/_ato20112014/2012/lei/112594.htm

Lei No 8.069, de 13 de julho de 1990. Dispõe sobre o estatuto da criança e do adolescente e dá outras providências. Diário Oficial da União, 14 jul. 1990. Recuperado de http://www.planalto.gov.br/ccivil_03/leis/18069.htm

Leite, V. (2012). A sexualidade adolescente a partir de percepções de formuladores de políticas públicas: Refletindo o ideário dos adolescentes sujeitos de direitos. Psicologia Clínica, 24(1), 89-103. https://doi.org/10.1590/S010356652012000100007

Leite, V. (2009). Sexualidade adolescente como direito? A visão de formuladores de políticas públicas (Dissertação de mestrado). Universidade do Estado do Rio de Janeiro, Rio de Janeiro, RJ, Brasil.

Lima, W., Severo, A., \& Maciel, A. (2013). Medida socioeducativa de internação de adolescentes: Uma reflexão sobre o direito de visita íntima. Direitos Fundamentais e Justiça, 7(24), 96-112. https://doi.org/10.30899/dfj.v7i24.251

Louro, G. (1997). Gênero, sexualidade e educação: Uma perspectiva pós-estruturalista (6a ed.). Petrópolis, RJ: Vozes.

Mattar, L. (2008). Exercício da sexualidade por adolescentes em ambientes de privação de liberdade. Cadernos de Pesquisa, 38(133), 61-95. https://doi.org/10.1590/S0100-15742008000100004

Melo, E. (2010). Direito e norma no campo da sexualidade na infância e adolescência. In: M. Ungaretti (Org.), Criança e adolescente: Direitos, sexualidade e reprodução (pp. 43-65). São Paulo, SP: Associação Brasileira de Magistrados, Promotores de Justiça e Defensores Públicos da Infância e da Juventude. Recuperado de: http://jornalggn.com.br/sites/default/files/documentos/livro_crianca_e_adolescente_direitos_sexualidades_reproducao.pdf

Montenegro, M. (2015). Um olhar sobre a pesquisa: dos espaços aos direitos: A realidade da ressocialização na aplicação das medidas socioeducativas de internação das adolescentes do sexo feminino em conflito com a lei nas cinco regiões. In: A. P. M. Costa, D. D. Eilberg, J. M. Goldani (Orgs.), Justiça juvenil na contemporaneidade (pp. 94-100). Porto Alegre, RS: Universidade Federal do Rio Grande do Sul

Moraes, A. (2001). A sexualidade de jovens nas instituições: Emoções, razões e políticas (Dissertação de mestrado). Universidade Federal do Rio de Janeiro, Rio de Janeiro, RJ, Brasil.

Moreira, F. (2012). Cadeias dominadas: Dinâmicas de uma instituição em trajetórias de jovens internos (Dissertação de mestrado). Universidade de São Paulo, São Paulo, SP, Brasil.

Nascimento, M. (2010). “Ladrão sim, bicha nunca!” Práticas homofóbicas entre adolescentes masculinos em uma instituição socioeducativa brasileira. Educação, Sociedade \& Culturas, (31), 67-81.

Pereira, P. (2016). Adolescentes e o exercício da sexualidade: uma análise no espaço de privação de liberdade. ARACÊ: Direitos Humanos em Revista, 3(4), 30-44.

Relatório da Conferência Internacional sobre População e Desenvolvimento: Plataforma de Cairo. (1994). Recuperado d: http://www.unfpa.org.br/Arquivos/relatorio-cairo.pdf

Silveira Filho, F. M. (2010). A crise da masculinidade contemporânea. In: H. Costa (Org.), Retratos do Brasil homossexual: Fronteiras, subjetividades e desejos (pp. 323-332). São Paulo, SP: Edusp. 
Aline Monteiro Garcia

Doutora em Psicologia pela Universidade Federal do Rio de Janeiro. Rio de Janeiro - RJ. Brasil. Professora do curso de Psicologia e da Pós-Graduação lato sensu em Saúde Mental e Atenção Psicossocial da Universidade Estácio de Sá (UNESA). Rio de Janeiro - RJ. Brasil. Pesquisadora vinculada ao Programa Pesquisa Produtividade da UNESA. Psicóloga do Departamento Geral de Ações Socioeducativas (DEGASE-RJ).

E-mail: alinegarcia.psic@gmail.com

(iD) https://orcid.org/0000-0002-6224-6378

\section{Hebe Signorini Gonçalves}

Doutora em Psicologia pela PUC-RIO. Professora do Instituto de Psicologia e do Programa de Pós-Graduação em Psicologia da Universidade Federal do Rio de Janeiro. Rio de Janeiro - RJ. Brasil.

E-mail: hebe@globo.com

(D) https://orcid.org/0000-0003-1688-9927

Recebido 24/08/2017

Aceito 07/05/2018

Received 08/24/2017

Approved 05/07/2018

Recibido 24/08/2017

Aceptado 07/05/2018

Como citar: Garcia, A. M. e Gonçalves, H. S. (2019). Sexualidade na medida socioeducativa de internação: traçando pistas por uma revisão da literatura. Psicologia: Ciência e Profissão, 39, 1-16. https://doi.org/10.1590/1982-3703003184463

How to cite: Garcia, A. M. e Gonçalves, H. S. (2019). Sexuality in the socio-educational measure of internment: tracing clues for a literature review. Psicologia: Ciência e Profissão, 39, 1-16. https://doi.org/10.1590/1982-3703003184463

Cómo citar: Garcia, A. M. e Gonçalves, H. S. (2019). Sexualidad en la medida socioeducativa de internación: trazando pistas por una revisión de la literatura. Psicologia: Ciência e Profissão, 39, 1-16. https://doi.org/10.1590/1982-3703003184463 